\title{
Políticas públicas para promover el turismo en La Pampa: agencias estatales, discursos y acciones para su desarrollo (1920-1960)
}

\author{
Public Policies for Promoting Tourism in La Pampa: State \\ Agencies, Speeches and Actions for its Development (1920- \\ 1960)
}

\section{Stella M. Cornelis}

Universidad Nacional de La Pampa

Argentina

DOI: https://doi.org/10.25032/crh.v6i10.6

Recibido: 31/03/2020

Aceptado: 09/05/2020

Resumen: Este artículo tiene como propósito analizar las políticas públicas para fomentar el turismo en el interior de la Argentina. Sin perder de vista el posicionamiento de ese tópico en la agenda del Estado nacional, nos centramos en los discursos que propugnaron la implementación de esas políticas, las agencias estatales que se crearon y las acciones desarrolladas para convertir al Territorio Nacional de La Pampa, provincia desde 1952, en un destino turístico. En este sentido, estudiamos los instrumentos que permitieron la ejecución de esas políticas como el entramado normativo y los dispositivos de gestión, es decir los recursos humanos, materiales y tecnológicos. En la gestación e implementación de las políticas públicas vinculadas al turismo se involucraron representantes gubernamentales que interpelaron a los actores de la sociedad civil; estos interlocutores también tuvieron un rol fundamental en ese proceso.

Palabras clave: Turismo, Políticas Públicas, Agencias Estatales, Interior Argentino.

Abstract This article has as purpose to analize the public policies to foment the tourism in the interior of Argentina. Without losing the point of view of the positioning of this topic in the agenda of the Nacional State, we focus on the speeches which propagate the implementation of this policies, the State agencies that were made and 
the actions developed to convert the National Territory of La Pampa, province since 1952, in a touristical destiny. In this sense, we study the instruments which allowed the execution of this policies like the normative framework and the management devices, in another words the human resources, materials and technologies. In the gestation and implementation of this public policies linked to tourism there were involved government representants who interpellated the actors of civil society; these interlocutors also had a fundamental rol on this process.

Key words: Tourism, Public Policies, State Agencies, Interior of Argentina.

\section{Introducción}

Indagar el turismo desde una perspectiva histórica nos sitúa ante múltiples intersecciones, que van desde su práctica vinculada al consumo y al tiempo libre, las costumbres de determinados sectores sociales, el acceso de los trabajadores a la posibilidad de vacacionar, las inversiones en infraestructura como son la construcción de caminos y hoteles, los beneficios para la salud que aportaba la vida al aire libre, entre muchas otras. En este sentido, es posible enfocarnos en su estudio desde la historia económica, social y cultural. El rol del Estado y las agencias específicas, encargadas de elaborar e implementar políticas públicas, es otra vía de entrada para acercarnos al turismo. Si bien este actor tuvo un papel central, tanto desde el plano legislativo como desde el control y regulación del tiempo libre, también interpeló a la sociedad civil, y a su vez fue intimado por esta, para accionar en esa materia (Ospital 63-84).

Nuestro marco de referencia remite a las indagaciones que ha realizado la historiadora Elisa Pastoriza (2011), ${ }^{1}$ y a los trabajos que estudiaron los estrechos vínculos entre el Estado y las instituciones privadas para impulsar las actividades turísticas. En esta línea se encuentran las obras que examinan el accionar del Touring Club y del Automóvil Club Argentino en la promoción de prácticas deportivas y de esparcimiento, relacionadas con los viajes por el territorio. ${ }^{2}$ Sin lugar a dudas la

\footnotetext{
${ }^{1}$ Esta publicación condensa, como aclara la autora, años de investigación sobre Mar del Plata como ciudad turística.

${ }^{2}$ Son varias las obras referentes al respecto: Ospital, 2005; Melina Piglia, «La incidencia del Touring Club Argentino y del Automóvil Club Argentino en la construcción del turismo como cuestión pública:
} 
incorporación del automóvil introdujo un cambio significativo en la posibilidad de realizar extensos recorridos por el interior del país. ${ }^{3}$ Las políticas sobre turismo social durante el peronismo también estimularon el interés de los investigadores, que se enfocaron en las acciones desplegadas por el gobierno para favorecer esas prácticas entre los sectores más desfavorecidos de la sociedad. ${ }^{4}$ Asimismo, se analizaron las transformaciones territoriales y urbanas en relación a la oferta turística en algunas ciudades como Mar del Plata, Necochea, Miramar, Córdoba o San Carlos de Bariloche. 5

Además, con una mirada en el largo plazo, algunos cientistas proponen una serie de etapas vinculadas con la emergencia de las políticas turísticas en el país. ${ }^{6}$ El estímulo estatal, la creación de agencias específicas como la Dirección de Parques Nacionales y la construcción de obras de infraestructura, hoteles y caminos son otras de las

1918-1929», Estudios, Perspectivas, Turismo, Vol. 17, N. ${ }^{\circ}$ 1, 2008a, pp. 51-70; "Asociaciones civiles y estado en los años veinte: intervenciones del Automóvil Club Argentino y del Touring Club Argentino en vialidad y turismo", EIAL, Vol. 19, N. ${ }^{\circ}$ 2, 2008b, pp. 119-140; Autos, rutas y turismo: El Automóvil Club Argentino y el Estado, Buenos Aires, Siglo Veintiuno Editores, 2014; Elisa Pastoriza y Melina Piglia, «Asociaciones civiles, empresas y Estado en los orígenes del Turismo Argentino", Anuario IEHS, Vol. 27, 2012, 393-415.

3 Anahí Ballent, «Kilómetro cero: la construcción del universo simbólico del camino en la Argentina de los años treinta», Boletín del Instituto de Historia Argentina Americana Dr. Emilio Ravignani, ${ }^{\circ} .^{\circ} 27$, 2005, pp. 107-136. Piglia, 2008a; Piglia, 2014; Melina Piglia, «Turismo en automóvil en Argentina (1920-1950)», Tiempo Social, Revista de Sociología da UPS, Vol. 30, ‥ ${ }^{\circ}$ 2, 2018, pp. 87-111. También los ferrocarriles tuvieron injerencia en el estímulo del turismo; consultar Elena Salerno, «Los inicios del turismo y los ferrocarriles del Estado en Argentina en las primeras décadas del siglo XX», VI Congreso de Historia Ferroviaria, 2012, pp. 1-18.

4 Eugenia Scarzanella, «El ocio peronista: vacaciones y «turismo popular» en Argentina (1943-1955)», Entrepasados, N. ${ }^{\circ}$ 14, 1998, pp. 65-84. Miguel Khatchikian y María Cristina Murray, «Turismo social: el paraíso perdido», Nexos, Vol. 6, N. ${ }^{\circ}$ 11, 1999, pp. 12-17. Elisa Pastoriza, «El turismo social en la Argentina durante el primer Peronismo. Mar del Plata, la conquista de las vacaciones y los nuevos rituales obreros, 1943-1955», Nuevo Mundo Mundos Nuevos [en línea], puesto en línea el 16/6/2008, pp. 1-14.

5 Pastoriza y Piglia, 2012; Pastoriza, 2011; Elisa Pastoriza y Juan Carlos Torre, «Mar del Plata, un sueño de los argentinos», en: Fernando Devoto y Marta Madero (eds.), Historia de la vida privada en la Argentina, Buenos Aires, Taurus, 1999, pp. 49-77. Pedro Navarro Floria, "La "Suiza argentina", de utopía agraria a postal turística: la resignificación de un espacio entre los siglos XIX y XX», $3 .{ }^{a s}$ Jornadas de Historia de la Patagonia, 2008, pp. 1-23.

${ }^{6}$ Alejandro Capanegra, «El desarrollo turístico como estrategia política del estado: de la política en turismo a la política turística. Argentina 1900-1975", Aportes y Transferencias, Vol. 14, N. ${ }^{\circ}$ 1, 2010, pp. 23-42. Erica Schenkel y Fernando Almeida, «La política turística y la intervención del Estado. El caso de Argentina», Perfiles Latinoamericanos, Vol. 46, N. ${ }^{\circ}$ 23, 2015, pp. 197-221. 
temáticas analizadas. ${ }^{7}$ Desde una perspectiva a escala regional la mayoría de las pesquisas se han centrado en el Parque Nacional Nahuel Huapi. ${ }^{8}$

Esta síntesis, que no tiene la pretensión de ser exhaustiva, sobre las producciones que analizan el turismo desde perspectivas diversas nos lleva a advertir que aún falta indagar el impacto que tuvieron las políticas nacionales en el interior argentino y las acciones concretas que se desarrollaron para darles respuesta. Este trabajo pretende ser un aporte en este sentido; nuestro propósito es partir de las transformaciones que sentaron las bases de las políticas públicas sobre turismo en Argentina y conocer cuál fue su trascendencia en el interior del país, específicamente en La Pampa. Así, nos enfocaremos en las acciones desarrolladas por las autoridades gubernamentales para convertir al territorio en un destino turístico y en los actores de la sociedad civil que participaron de la gestación y aplicación de esas políticas. Ese proceso implicó la creación de agencias estatales y la elaboración de normativas, aspectos que también examinaremos.

\section{La cuestión del turismo en la agenda del Estado nacional}

La coyuntura iniciada entre la primera guerra mundial y la posguerra instaló en la agenda pública nacional el tema relacionado con el turismo. En ese contexto dos instituciones de la sociedad civil efectuaron demandas al Estado, como la construcción de caminos, ferrocarriles y hoteles, para que promocionara y regulara esa actividad (Piglia 2008b 119-140). El Touring Club y el Automóvil Club Argentino concibieron esas prácticas desde múltiples dimensiones: como industria, como un medio para «civilizar», en relación con la salud pública, la armonía social y el patriotismo. En ese sentido, realizaron diversas gestiones como la realización de eventos, entre los que

\footnotetext{
7 Eugenia Scarzanella, «Las bellezas naturales y la nación: los parques nacionales en Argentina en la primera mitad del siglo XX», Revista Europea de Estudios Latinoamericanos y del Caribe, $\mathrm{N}^{\circ}{ }^{0} 73,2002$, pp. 5-21. Melina Piglia, «El despertar del turismo: primeros ensayos de una política turística en la Argentina (1930-1943)», Journal of Tourism History, Vol. 13, 2011, pp. 57-74. Melina Piglia, «En torno a los Parques Nacionales: primeras experiencias de una política turística nacional centralizada en la Argentina (1943-1950)», Pasos. Revista de Turismo y Patrimonio Cultural, Vol. 10, N. ${ }^{0}$ 1, 2012, pp. 6173 .

8 Paula Núñez y Laila Vejsbjerg, «El turismo, entre la actividad económica y el derecho social. El Parque Nacional Nahuel Huapi, Argentina, 1934-1955", Estudios y Perspectivas en Turismo, Vol. 19, N. ${ }^{\circ} 6$, 2010, pp. 930-945. Laura Méndez, Estado, frontera y turismo. Historia de San Carlos de Bariloche, Buenos Aires, Prometeo, 2010. Giulietta Piantoni, Gonzalo Barrios García y Liliana Pierucci, «Las bellezas panorámicas argentinas: una revisión histórica de las políticas públicas y el desarrollo del turismo en el Parque Nacional Nahuel Huapi durante el peronismo (1943-1955)», Pasado Abierto, N. ${ }^{\circ}$ 9, 2019, pp. 236-255.
} 
podemos mencionar el Primer Congreso Nacional de Vialidad (1922), la Exposición de Vialidad, Transportes y Turismo (1926), elaboraron un proyecto de Ley de vialidad que elevaron al Congreso Nacional-, convocaron al Primer Congreso Sudamericano de Turismo (1928) que culminó con la conformación de la Federación Sudamericana de Turismo; también organizaron la Primera Conferencia Nacional de Turismo (1927), entre otras acciones. 9 Tanto los congresos como los nacientes organismos tuvieron un papel destacado en la interpelación al Estado en materia de políticas orientadas a esa temática.

Las consecuencias económicas de la crisis llevaron a redefinir y reforzar la intervención del Estado en los años treinta. El esquema espacial que caracterizó el período de «crecimiento hacia afuera», con su desproporcionado desarrollo del litoral frente a un interior escasamente vinculado a los circuitos productivos, fue cuestionado (Ballent y Gorelik 146). La difusión del automotor y la necesidad de conformar un mercado interno, se conjugaron para propiciar la construcción de caminos modernos que permitieron la integración de diversas regiones del país. ${ }^{10}$ Así, la tríada petróleo, ${ }^{11}$ automóvili2 y camino colaboró con el progreso del turismo. Otros factores favorecieron esa actividad: la crisis económica y el control de cambios que imposibilitaron a varios integrantes de la élite realizar sus tradicionales viajes a Europa, nuevas disposiciones legislativas que permitieron mayor disponibilidad del tiempo libre como el sábado inglés (1932) o las vacaciones pagas para el sindicato de comercio (1934), las rebajas en tarifarias de trenes turísticos, entre otras.

\footnotetext{
9 Piglia, 2008a; Melina Piglia, «De la Dirección de Parques Nacionales, a la Administración General de Parques Nacionales y Turismo: primeras experiencias de una política turística nacional centralizada (1934-1950)», V Jornadas de Historia Política «Las provincias en perspectiva comparada», 2010; Piglia, 2014.

10 En este sentido, adquirió considerable relevancia la Dirección de Vialidad Nacional, creada en 1932 mediante la Ley Nacional N. ${ }^{\circ} 11658$ y bajo la dependencia del Ministerio de Obras Públicas. Estas políticas se orientaron en un primer momento a integrar el territorio - y el mercado interno- por medio de la red vial; en una segunda etapa, el Estado se involucró con el desarrollo turístico. Consultar Ballent, 2005 y Anahí Ballent, «Ingeniería y Estado: la red de caminos y las obras públicas en Argentina, 19301943", Historia, Ciencia e Saude-Manguinhos, Vol. 15, N. ${ }^{3}$, 2008, pp. 827-847; Ospital, 2005.

${ }^{11}$ Si bien Yacimientos Petrolíferos Fiscales (YPF) fue creada durante el primer gobierno de Yrigoyen, en 1932 se aprobó la primera Ley Nacional de Petróleo y en 1934 se limitaron las concesiones privadas. Las campañas publicitarias de YPF la asociaban a la integración del país por medio del automóvil. Así, se impulsó el automovilismo deportivo y el turismo. Véase al respecto Ballent y Gorelik, 2001.

12 Hacia comienzos de la década del treinta Argentina se encontraba en marcada desventaja, en comparación con Estados Unidos, Australia o Canadá, respecto de la construcción de carreteras. Así, el número de automóviles en relación con los kilómetros construidos era muy alto. Consultar Ospital, 2005 .
} 
Desde el punto de vista turístico fueron dos las gestiones concretas del Estado: el diseño de políticas para el territorio nacional y la promoción de obras como la construcción de caminos (Ospital 2005). Una de las primeras medidas fue la creación de la Dirección de Parques Nacionales ${ }^{13}$ en 1934 - Ley N. ${ }^{0} 12103-$, bajo la órbita del Ministerio de Agricultura. A partir del lema «conocer la patria es un deber» esta repartición se ocupó de los parques existentes -Iguazú que surgió en 1902 y Nahuel Huapi en 1916-. El accionar de esa agencia estatal se orientó a la conservación, forestación, protección de especies autóctonas, también se vinculó con tareas como la construcción de enclaves articulados por medio de la infraestructura vial y hotelera, que permitiera el desarrollo de actividades turísticas. En 1937 se sumaron a los parques existentes otros espacios como Lanín, Puelo, Los Alerces, Perito Moreno y Los Glaciares. La política del organismo estuvo orientada a la afirmación de la soberanía territorial y al desarrollo regional de áreas de frontera y o periféricas. ${ }^{14} \mathrm{El}$ parque Nahuel Huapi y la ciudad de Bariloche concitaron la mayor atención del nuevo organismo. Precisamente, desde la Dirección se programó la construcción del hotel Llao-Llao -inaugurado en 1938-, la pavimentación de caminos, la construcción del Centro Cívico, la instalación de servicios de transporte público, se efectuaron campañas publicitarias, entre otras gestiones. ${ }^{15}$

A partir de los años treinta se evidenció una mayor presencia de la «cuestión turística» en la agenda del Estado nacional, que se materializó en la instauración de agencias para implementar políticas públicas relacionadas con ese tópico. La creación de Dirección Nacional de Turismo en 1938, aunque no llegó a ponerse en marcha por

\footnotetext{
${ }^{13}$ La creación de áreas protegidas en Argentina data del año 1903, cuando Francisco P. Moreno efectuó una donación de 7500 hectáreas de tierras al Estado Nacional. Así surgió en 1922 el Parque Nacional del Sur, más tarde denominado Nahuel Huapi; fue el primero de Sudamérica. La figura de Parque Nacional se adoptó en el país siguiendo el concepto formulado en Norteamérica, es decir que en sus orígenes se encuentra el objetivo de preservar las bellezas escénicas y paisajísticas. Sin embargo, a lo largo de su historia, fue modificándose su estructura hasta llegar a cubrir distintos propósitos: ambientales, culturales, científicos, educativos y sociales. Consultar Scarzanella, 2002.

14 Los parques nacionales fueron pensados como «avanzadas de nacionalidad», se encontraban lejanos a los centros poblados, en territorios nacionales que a su vez eran áreas fronterizas. La presencia del Estado central se reforzaba por medio de funcionarios viales y de la Dirección de Parques Nacionales. Véanse Ospital, 2005 y Piglia, 2010.

15 Piglia, 2010; Laura Méndez, «Turismo de elite y turismo social en el «Edén de América». El parque Nacional Nahuel Huapi entre 1934 y 1955", Textos y contextos desde el sur, Vol. II, N. ${ }^{\circ}$ 4, 2016, pp. 1330. Desde principios del siglo Xx existieron varios proyectos relacionados con incentivar el turismo en San Carlos de Bariloche y en los años veinte la ciudad se convirtió en un centro turístico relacionado con los deportes de montaña. Pedro Navarro Floria y Laila Vejsberg, «El proyecto turístico barilochense antes de Bustillo. Entre la prehistoria del Parque Nacional Nahuel Huapi y el desarrollo local», Estudios y perspectivas en turismo, Vol. $18, \mathrm{~N}^{\circ}{ }^{0}$, 2009, pp. 414-433.
} 
dificultades económicas, fue un jalón inicial. Dieron continuidad a esa medida la aprobación de la Ley N. ${ }^{\circ} 12.699$ que fomentaba el turismo; a comienzos de los años cuarenta se instituyó el Consejo Nacional de Turismo y, sobre la base de esas experiencias, en 1942 se presentó un proyecto de ley para la conformación de la Dirección Nacional (Piglia 2010). ${ }^{16}$ También en este período se crearon la mayor cantidad de organismos provinciales relacionados con la gestión del turismo: Mendoza en 1936, Córdoba en 1938, La Rioja en 1939, Santiago del Estero y San Juan en 1941 y Tucumán en 1942 (Capanegra 2010).

Luego del golpe militar de 1943 la Dirección de Turismo se anexó a la Dirección de Parques Nacionales, la que a principios de 1945 se convirtió en Administración General de Parques Nacionales y Turismo. Hacia 1951 esta agencia estatal se dividió en la Dirección de Parques Nacionales, dependiente del Ministerio de Agricultura, y la Dirección de Turismo quedó bajo la órbita del Ministerio de Transporte (Piglia 2010). La política implementada durante los primeros años de la gestión peronista se centró en el desarrollo del turismo social. ${ }^{17}$ En el contexto de la «democratización del bienestar» buscó garantizar el acceso de los trabajadores y sectores desprotegidos de la sociedad al goce de las prácticas turísticas y recreativas; el turismo comenzó a percibirse como un derecho laboral y social (Pastoriza y Torre 2002). Una serie de medidas aprobadas durante esas gestiones incentivaron aún más esas prácticas: el aumento de los salarios, la generalización del descanso semanal, los días feriados, el aguinaldo, el derecho a vacaciones pagas, entre otras (Troncoso y Lois 2004 281-94). Además, se asignaron oficialmente fondos para cumplir con esos propósitos y se efectuó un gran montaje propagandístico (Pastoriza y Pedetta 2009 1-20). El Segundo Plan Quinquenal presentó un capítulo específico dedicado al turismo. El propósito fundamental era posibilitar el acceso del pueblo al conocimiento de las bellezas naturales del país, aprovechar los beneficios del descanso físico y espiritual que

\footnotetext{
${ }^{16}$ La creación de agencias no implicó la puesta en marcha de un aceitado funcionamiento y la implementación de políticas concretas. Como plantea Piglia la coyuntura de la segunda guerra mundial fue una de las causas que afectó negativamente la posibilidad de realizar viajes; otro motivo fue la falta de recursos de la repartición.

${ }_{17}$ Pastoriza, 2008; Elisa Pastoriza y Juan Carlos Torre, «La democratización del bienestar», en: Torre, Juan Carlos (ed.), Los años peronistas (1943-1955), Buenos Aires, Sudamericana, 2002, pp. 257-313; Scarzanella, 1998.
} 
proporcionaba el turismo y facilitar la llegada del mayor número posible de extranjeros para que conocieran el país. ${ }^{18}$

El turismo, en tanto política de Estado, se desdobló en dos dimensiones con posterioridad al golpe militar de 1955: una central, que lo ubicó en la agenda de política económica y, otra secundaria, que lo conservó en el ámbito de la agenda social. Los Decretos-Leyes 6325/56 y 8014/57 crearon la Dirección Nacional de Turismo, y en 1957 el Decreto-Ley N. ${ }^{0} 12028$ organizó esa entidad, que contó con una comisión asesora integrada por representantes de la Dirección de Parques Nacionales, la Comisión Nacional de Museos, Monumentos y Lugares Históricos (Capanegra 2010 23-42). Finalmente, durante el gobierno de Frondizi se sancionó la Ley N. ${ }^{\circ}$ 14574/58, reglamentada luego por el Decreto N. ${ }^{\circ} 9468 / 61 .^{19}$

En el contexto de las políticas desarrollistas el turismo fue concebido como una industria, de las denominadas «sin chimeneas». ${ }^{20}$ La creación del Consejo Nacional de Desarrollo (Conade) en 1961, ${ }^{21}$ permitió la conformación de «equipos de trabajo, el análisis de las distintas situaciones nacionales y la generación de propuestas de desarrollo sectorial» (Jauregui 2013 265-66), y en el marco de esas transformaciones se prestó atención al turismo. Con el objetivo de planificar políticas en la materia se firmó en 1967 un convenio entre la Dirección Nacional de Turismo y la Facultad de Arquitectura de la Universidad de Buenos Aires (UBA), para realizar investigaciones sobre su incidencia en las economías regionales, que contó con asesoramiento de expertos de la Organización de Estados Americanos (OEA). Un año más tarde se elaboró

\footnotetext{
18 Presidencia de la Nación, Subsecretaría de Informaciones. Segundo Plan Quinquenal (1952-1957), Buenos Aires, 1953, pp. 153-155.

19 República Argentina, Decreto Nacional N. ${ }^{\circ} 9468$ del 19 de octubre de 1961, Reglamentario de la Ley N. ${ }^{\circ}$ 14574. Disponible en: http://www.saij.gob.ar/9468-nacional-decreto-reglamentario-ley-14.574sobre-direccion-nacional-turismo-dn19610009468-1961-10-19/123456789-0abc-864-90001691soterced.

${ }^{20}$ La Resolución N. ${ }^{0} 56$ de la CEPAL (1953) consideraba que el turismo era una de las vías eficaces para incrementar el desarrollo económico de un país. Comisión Económica Para América Latina-Consejo Económico y Social, «Resolución N. ${ }^{\circ} 56$ del 25 de abril de 1953». Suplemento N. ${ }^{\circ}$ 3, Disponible en: http://repositorio.cepal.org/bitstream/handle/11362/15630/RES-056-S-V_es.pdf.

${ }^{21}$ Otro hito importante fue la creación del Consejo Federal de Inversiones (CFI) en 1959, con el fin de orientar las inversiones hacia todos los sectores del territorio nacional. También en los años sesenta se crearon las carreras oficiales universitarias y terciarias relacionadas con el turismo. Analía Almirón, Rodolfo Bertoncello, Diego Kuper y Lucas Ramírez, «El turismo como impulsor del desarrollo en Argentina. Una revisión de los estudios sobre la temática», Aportes y transferencias, Año 12, Vol. 1, 2008, pp. 56-86.
} 
un Documento de trabajo para la planificación turística en el país. ${ }^{22}$ En ese contexto también se aprobó la Ley N. ${ }^{0}$ 17752/68 de promoción para la construcción de hoteles para el turismo internacional. 23 Esta legislación se complementó en años posteriores con las leyes sobre hotelería N. ${ }^{0} 18828 / 70,{ }^{24}$ de regulación de agencias de viaje N. ${ }^{0}$ 18829/70, 25 de promoción de lugares turísticos del país e instalación de oficinas de turismo en estaciones terminales N. ${ }^{0}$ 21056/75. ${ }^{26}$ También, en esa misma línea de acciones, Argentina se incorporó a la Organización Mundial de Turismo (OMT) y fueron aprobados sus estatutos mediante la Ley N. ${ }^{\circ} 19644 / 72 .{ }^{27}$

A partir de estas gestiones implementadas por el Estado nacional, entre las décadas del veinte y del sesenta, que sentaron las bases de las políticas públicas sobre turismo en Argentina nos interrogamos sobre el impacto que tuvieron en La Pampa y las respuestas de las autoridades gubernamentales y los actores de la sociedad civil.

\section{La trama de agencias estatales para impulsar el turismo en La Pampa}

${ }^{22}$ Ese documento se denominó «Bases metodológicas para la planificación del turismo como factor de desarrollo nacional». Asimismo, se efectuó un inventario sobre patrimonio turístico nacional, para que sirviera de apoyo a la planificación en turismo. Alejandro Capanegra, «Política turística Argentina 1956-1976. De la agenda social a la agenda económica», ponencia presentada en el VI Congreso Latinoamericano de Investigación Turística, Neuquén, 2014.

${ }^{23}$ Proyectaba la construcción de hoteles en las ciudades de Buenos Aries, San Carlos de Bariloche, Mendoza, Jujuy, Salta y en los Parques Nacionales Nahuel Huapi e Iguazú. También estipulaba que el Poder Ejecutivo podía incluir nuevas localidades y establecía exenciones impositivas para las empresas que explotaran estos emprendimientos hoteleros. República Argentina, Ley N. ${ }^{\circ}$ 17752, del 27 de mayo de 1968, Promoción de la construcción de hoteles de turismo internacional. Disponible en: http://servicios.infoleg.gob.ar/infolegInternet/anexos/230000-234999/232558/norma.htm.

República Argentina, Decreto N. ${ }^{\circ}$ 3.091, del 3 de junio de 1968 , reglamentario de la Ley N. ${ }^{\circ} 17.752$ sobre Promoción de la construcción de hoteles de turismo internacional. Disponible en: http://www.saij.gob.ar/3091-nacional-decreto-nacional-ley-17752-sobre-promocion-construccionhoteles-turismo-internacional-dn19680003091-1968-06-03/123456789-0abc-190-30008691soterced.

${ }^{24}$ República Argentina, «Ley N. ${ }^{\circ} 18.828$ del 6 de noviembre de 1970, sobre Reglamentación Hotelera». Disponible en: http://servicios.infoleg.gob.ar/infolegInternet/anexos/230000234999/231822/norma.htm

${ }_{25}$ República Argentina, «Ley N.o 18.829 del 6 de noviembre de 1970, sobre Reglamentación de los agentes de viaje». Disponible en: http://servicios.infoleg.gob.ar/infolegInternet/anexos/2500029999/27128/norma.htm

${ }^{26}$ República Argentina, «Ley N. ${ }^{0} 21.056$ del 17 de septiembre de 1975, sobre Medidas promocionales sobre turismo en Transportes de media y larga distancia». Disponible en: https://leyesargentinas.com/norma/233112/ley-21056-turismo-transportes-de-media-y-largadistancia-medidas-promocionales\#texto-original

${ }_{27}$ Erica Schenkel, «La política turística como alternativa económica en la Argentina», Pasos. Revista de Turismo y Patrimonio Cultural, Vol. 13, N. ${ }^{\circ}$ 3, 2015, pp. 619-628. República Argentina, «Ley N..$^{\circ}$ 19.644, del 16 de mayo de 1972, Apruébanse los Estatutos de la Organización Mundial del Turismo». Disponible en: http://servicios.infoleg.gob.ar/infolegInternet/anexos/215000-219999/217313/norma.htm 
Las primeras resoluciones en materia de políticas turísticas que hemos identificado se concretaron durante la gestión del gobernador Miguel Duval28. Este mandatario envió notas a los presidentes del Touring Club, del Automóvil Club Argentino y a la Dirección de Parques Nacionales solicitándoles recomendaran a los turistas, en tránsito hacia el sur, el empleo de las rutas pampeanas. Asimismo, por intermedio de la Oficina de Prensa de la Gobernación realizó una activa campaña, en periódicos y publicaciones locales y nacionales, con el objetivo de publicitar y estimular el paso de las corrientes turísticas por el territorio pampeano. El gobernador evaluó de manera positiva esas medidas al exponer que durante la temporada de verano 19391940 el encargado del destacamento policial, ubicado junto a la balsa del paraje La Japonesa, registró «el paso de más de un millar de turistas». ${ }^{29}$ De esta manera, advertimos como la «cuestión» del turismo ingresó a la agenda del Estado pampeano. ${ }^{30}$

La proyección de políticas públicas entrañó en paralelo la creación de agencias estatales específicas. Por iniciativa de Duval se constituyó en 1941 la Comisión Oficial de Propaganda y Fomento del Territorio de La Pampa. En consonancia con esa medida el gobernador dispuso la creación de un fondo de recursos para sufragar los gastos que demandara la divulgación, ${ }^{31}$ dentro y fuera del territorio, de los aspectos de carácter cultural, social, histórico, geográfico, económico y edilicio que ofrecía La Pampa. Esa comisión tuvo una actuación fugaz, ya que se disolvió el $1^{0}$ de septiembre de 1943. Sin embargo, ese mismo año se organizó una nueva entidad que amplió su espectro de acción al encargarse del Fomento, el Turismo y los Deportes. Quedó constituida por dos delegados del gobierno territoriano, uno de la administración de obras sanitarias

\footnotetext{
${ }^{28}$ Fue gobernador del Territorio Nacional de La Pampa durante los años comprendidos entre 1939 y 1946.

${ }^{29}$ Se denominaba La Japonesa al paraje ubicado en la vera del Río Colorado, límite entre La Pampa y Río Negro. Miguel Duval, Memoria presentada al Superior Gobierno de la Nación, Período: 1940-1941, Santa Rosa, Talleres Gráficos de la Gobernación de la Pampa, 1941, p. 107.

3o Retomamos el planteo teórico de Oszlak y O’Donell, quienes sugieren que las políticas estatales son paralelas a un proceso social, tejido alrededor de un tema o cuestión que las origina. Estas cuestiones están relacionadas con necesidades y/o demandas sociales. En este sentido, cuando el Estado toma posición genera respuestas de otros actores sociales, inclusive de otras reparticiones dentro de este. Oscar Oszlak y Guillermo O’Donnell, «Estado y políticas estatales en América Latina: hacia una estrategia de investigación», Doc. CEDES/G.E, Clacso/ N. ${ }^{\circ}$, Buenos Aires, Clacso, 1976.

31 Contribuyeron las municipalidades y comisiones de fomento, también colaboraron distintos propietarios, clubes, establecimientos industriales, escuelas, cooperadoras policiales, asociaciones de inmigrantes, entre otras asociaciones. Libro de Actas de la Comisión Oficial de Propaganda y Fomento del Territorio Nacional de La Pampa, Fondo de Gobierno, Archivo Histórico Provincial «Profesor Fernando Aráoz», Santa Rosa-La Pampa, Año 1942.
} 
la Nación, un representante del Automóvil Club Argentino y otro de la Administración de Vialidad Nacional. ${ }^{22}$ Sus miembros eran designados por el gobernador y funcionaba con recursos provenientes de diversos ámbitos. 33 De esta manera, en consonancia con el planteo de Melina Piglia, observamos cómo se trató de potenciar y articular estas políticas con la actividad privada, constituyéndose los directorios de las agencias estatales con representantes de diferentes reparticiones, corporaciones y asociaciones civiles (2011 57-74).

Para desempeñar sus tareas de manera más eficiente la Comisión dividió las funciones en tres sectores: fomento, turismo y deportes. Recién en el año 1945 se aprobó la reglamentación que establecía su funcionamiento. Particularmente el sector que nos compete tenía como atribuciones todo lo relacionado con el «turismo de tránsito y turismo local».34 Esa repartición debía coordinar sus funciones con la dirección nacional y las direcciones oficiales, provinciales y territoriales de turismo. La normativa establecía las actividades a implementar, que involucraban el estudio y la determinación de las zonas para excursiones en el territorio, el acceso a esos lugares y la recepción de los viajeros. La llegada de los turistas estaba sujeta a las empresas de transporte o bien su arribo podía producirse por medio del automóvil. Por ello otra de las gestiones de la comisión fue fomentar y unificar las iniciativas de las empresas de transporte para facilitar el acceso y la circulación en lugares turísticos. La recepción de excursionistas también se supeditaba a la capacidad hotelera, en este sentido los

\footnotetext{
${ }^{32}$ A su vez se creó un Comité Consultivo de la Comisión, compuesto por un representante de cada una de las siguientes reparticiones y organismos: la Dirección Nacional de Vialidad, la Dirección de Correos y Telégrafos, el Centro de Estudios Pampeanos, la asociación o asociaciones que agrupen a los comerciantes minoristas, las agrupaciones agropecuarias, las agrupaciones industriales, el congreso permanente de maestros de La Pampa. También preveía representantes de arquitectura, de las empresas ferroviarias y de transporte, de las asociaciones civiles, de las instituciones de turismo y automovilismo, de las organizaciones deportivas y de la industria hotelera. Libro de Actas de la Comisión de Fomento, Turismo y Deporte, Fondo de Gobierno, Archivo Histórico Provincial «Profesor Fernando Aráoz», Santa Rosa-La Pampa, 1943-1947, pp. 62-66.

33 Los recursos presupuestarios provenían de: a) la asignación que fijara el presupuesto de la Nación, b) los aportes que establecían las municipalidades y comisiones de fomento, c) las subvenciones, donaciones y aportes de las entidades privadas vinculadas al fomento y turismo del territorio, d) el producto del arrendamiento de locales o servicios, e) el producto de la venta o arriendo de material de publicidad, f) los fondos creados por ordenanzas municipales destinados al turismo y su fomento en el territorio de La Pampa, g) los fondos provenientes de fiestas que sean destinados en todo o en parte especialmente a esta comisión. Libro de Actas de la Comisión, de Fomento, Turismo y Deporte, Fondo de Gobierno, Archivo Histórico Provincial «Profesor Fernando Aráoz», Santa Rosa-La Pampa, 19431945 , p. 67.

34 Boletín Oficial de la Gobernación, «Resolución N. ${ }^{\circ} 1008$ del 22 de mayo de 1945, sobre reorganización de la Comisión Oficial de Fomento, Turismo y Deportes de La Pampa», Archivo Histórico Provincial «Profesor Fernando Aráoz», Santa Rosa-La Pampa.
} 
miembros de la entidad tenían que sugerir cuáles eran las mejoras necesarias en el servicio hotelero y homologar los precios en la forma establecida por la Dirección Nacional de Turismo.

La experiencia de la Comisión Oficial de Fomento, Turismo y Deportes fue también muy breve, ya que el 25 de julio de 1947 terminó disolviéndose. La principal causa de ese final fue la falta de recursos, que imposibilitaron la concreción de sus propósitos. Dos años más tarde, en el marco de la reforma constitucional de 1949, se produjo una reorganización de los ministerios, que conllevó una creciente burocratización y racionalización (Berrotarán 131-155); en ese contexto se modificó la organización burocrática-administrativa de la Gobernación de la Pampa.35 Así, se crearon y rediseñaron nuevas reparticiones públicas y surgió la Sección Turismo, dependiente de la Subsecretaría de Fomento. Entre las funciones previstas en el organigrama para el novel organismo destacamos: confeccionar un registro de hoteles, fomentar viajes culturales, redactar guías de turismo, elaborar proyectos para embellecer caminos y lugares destinados a vacacionar. También debía encargarse de la inspección y el fomento de la infraestructura necesaria -hosterías, hoteles, casas de hospedaje-, mejorar los medios de transporte y comunicación, brindar información turística, entre muchas otras. ${ }^{36}$ Vemos así como en la reestructuración de las reparticiones del Estado territoriano cristalizó una agencia específica dedicada al turismo. Ello estaba en correspondencia con la relevancia que el peronismo otorgó al turismo social. Igualmente, estas medidas mantenían continuidad con las políticas previas. El accionar de la Sección Turismo, al igual que sus precedentes, fue acotado por la falta de presupuesto.

El tránsito de territorio nacional a provincia implicó la proyección y creación de nuevas agencias estatales;37 los asuntos ligados al turismo quedaron momentáneamente bajo la órbita de la Dirección de Arquitectura y Construcciones,

\footnotetext{
35 La creación de nuevos organismos sentó las bases para la conformación de una élite estatal, encargada de realizar las políticas peronistas y permitir el tránsito de un estado territoriano a otro provincial. Fabio Alonso, «Transformaciones políticas en La Pampa chacia un estado peronista?», $4 \cdot^{\text {as }}$ Jornadas de Historia de La Patagonia, 2010.

${ }_{36}^{6}$ República Argentina, Ministerio del Interior, «Reorganización administrativa de la Gobernación del Territorio Nacional de La Pampa», 10 de mayo de 1949, Archivo Histórico Provincial «Profesor Fernando Aráoz», Santa Rosa-La Pampa, Fondo de Gobierno, Caja N. ${ }^{\circ} 127$.

37 Cabe aclarar que La Pampa se convirtió en provincia mediante la Ley N. ${ }^{0} 14037$, promulgada el 8 de agosto de 1951; se denominó Provincia Eva Perón hasta el año 1955.
} 
que dependía del Ministerio de Obras Públicas y Asuntos Agrarios. ${ }^{8}$ Las transformaciones instituidas por la «revolución libertadora» iniciaron un período de intervención en la recientemente creada provincia Eva Perón. En ese contexto fue la figura de Ismael Amit, 39 quien retomó las cuestiones relacionadas con la temática; en 1959, durante su gestión, se creó la Oficina Provincial de Turismo. Lo llamativo es que a pesar del interés que se demostró en estos asuntos, se organizó la repartición como una oficina y no como dirección, evitándose así las erogaciones presupuestarias.

La finalidad de esa agencia era promover, organizar y coordinar las actividades turísticas; desarrollar acciones permanentes de propaganda y difusión con el objeto de «posibilitar el acceso del pueblo al conocimiento de las bellezas naturales y demás elementos de atracción turística de la provincia» y «observar las actividades de empresas, comercios, industrias, atracciones, entidades particulares, servicios públicos, hoteles, etc., que se vinculen directamente con las prácticas del turismo».40 Sus compromisos eran varios, destacamos la elaboración de un plan de labor anual, la conservación de monumentos y lugares históricos, la creación y habilitación de zonas de descanso, informar, asesorar y orientar a los turistas, entre muchas otras obligaciones.

En los años sesenta la oficina de turismo se convirtió en Departamento Provincial de Turismo y a comienzos de la década siguiente tuvo distintas denominaciones: Dirección de Juventud, Deportes, Recreación y Turismo Social (19711973), Dirección de Turismo (1974-1976) y Secretaría de Difusión y Turismo a partir de 1976. Más allá de esos cambios en la nominación, sus objetivos eran similares a los de las agencias creadas con anterioridad.

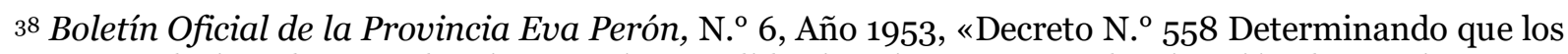
asuntos relacionados con el turismo serán atendidos interinamente por la Dirección de Arquitectura y Construcciones del Ministerio de Obras Públicas y Asuntos Agrarios», Archivo Histórico Provincial «Profesor Fernando Aráoz», Santa Rosa-La Pampa.

39 Interventor provincial entre 1958 y 1959, fue electo gobernador en 1960 y se desempeñó al frente del Poder Ejecutivo Provincial hasta 1962. Entre 1963-1966 nuevamente ganó las elecciones. «Llevó adelante una gestión inmersa en el clima ideológico de confianza en el progreso y en la capacidad de las políticas públicas para lograr los caminos deseados»; Mirta Zink, Marisa Moroni, Norberto Asquini y María Esther Folco, «Historia política, orden institucional y construcción de ciudadanía en La Pampa», en: Lluch, Andrea y Di Liscia, María Silvia (eds.), Historia de La Pampa II. Sociedad, política y economía de la crisis del treinta a inicios del nuevo siglo, Santa Rosa, EdUNLPam, 2011, p. 103.

$4^{40}$ Boletín Oficial de la Provincia de La Pampa, N. ${ }^{\circ}$ 282, «Decreto N. 793 del 29 de abril de 1960, Reglamentando el funcionamiento de la Oficina Provincial de Turismo», Fondo de Gobierno, Archivo Histórico Provincial Profesor Fernando Aráoz, Santa Rosa-La Pampa, pp. 377-379.
} 
Tabla 1. Agencias estatales de Turismo en La Pampa (1941-1976)

\begin{tabular}{|l|l|c|}
\hline Jurisdicción & Denominación de la Agencia & Años \\
\hline \multirow{2}{*}{$\begin{array}{l}\text { Territorio } \\
\text { Nacional de La }\end{array}$} & Comisión de Fomento y Propaganda & $1941-1943$ \\
\cline { 2 - 3 } & Comisión de Fomento, Turismo y Deporte & $1943-1947$ \\
\cline { 2 - 3 } $\begin{array}{l}\text { Sección Turismo (dependiente de la Subsecretaría de } \\
\text { Fomento) }\end{array}$ & $1949-1951$ \\
\hline \multirow{5}{*}{$\begin{array}{l}\text { Provincia Eva } \\
\text { Pampa }\end{array}$} & $\begin{array}{l}\text { "Asuntos sobre Turismo» (dependientes de la Dirección de } \\
\text { Arquitectura y Construcciones, bajo la órbita del Ministerio de } \\
\text { Obras Públicas) }\end{array}$ & $1951-1955$ \\
& $\begin{array}{l}\text { Oficina Provincial de Turismo (dependiente de la } \\
\text { Subsecretaría de Obras Públicas) }\end{array}$ & $1959-1966$ \\
\cline { 2 - 3 } & Departamento Provincial de Turismo. & $1966-1970$ \\
\cline { 2 - 3 } & $\begin{array}{l}\text { Dirección de Juventud, Deportes, Recreación y Turismo Social } \\
\text { (dependiente de la Secretaría de Promoción y Asistencia a la }\end{array}$ & $1971-1973$ \\
\cline { 2 - 3 } & $\begin{array}{l}\text { Comunidad) } \\
\text { Dirección de Turismo (dependiente de la Secretaría de }\end{array}$ & $1974-1976$ \\
\hline
\end{tabular}

Elaboración propia a partir de Boletines Oficiales del Territorio Nacional de La Pampa (1940-1951), Boletines Oficiales de la Provincia Eva Perón y Boletines Oficiales de la Provincia de La Pampa (1959-1076).

En la tabla 1 extractamos la trayectoria de las agencias que se crearon para promocionar el turismo en La Pampa. En ese derrotero estuvieron bajo la órbita de Obras Públicas, de la Secretaría de Promoción y Asistencia a la Comunidad o la Secretaría de Difusión y Turismo; además pasaron por diferentes denominaciones: sector, oficina, departamento y, finalmente, se constituyó como dirección. Sin dudas, ello demuestra la labilidad de esas agencias; la fugacidad de su existencia estaba atada a la falta de recursos materiales para funcionar. Sin embargo, más allá de sus magros presupuestos los funcionarios gubernamentales encararon el desafío de gestar políticas con el propósito de convertir al territorio en un atractivo para los visitantes.

\section{Transformar a La Pampa en un destino turístico: discursos y gestiones}

A lo largo de las décadas estudiadas existió, respecto de los discursos referidos al turismo, una notoria continuidad. Los mandatarios remarcaron la ubicación geográfica de La Pampa como «lugar apropiado para orientar las corrientes de turismo hacia la región de los lagos ».41 $\mathrm{Al}$ encontrarse situada en el centro del país, la estrategia fue captar a los viajeros en tránsito hacia otras regiones, especialmente aquellos que se dirigían al sur del país.

A fines de los años cincuenta y durante los sesenta, los funcionarios valoraron el turismo en tanto actividad importante desde el punto de vista económico, cultural, científico e histórico. En esa época también se hizo hincapié en desvirtuar la idea

\footnotetext{
${ }_{41}$ Duval, 1941; La Pampa Hoy, 1969, p. 12.
} 
errónea de que La Pampa carecía de atractivos turísticos, al argumentar que contaba con

... lugares de sorprendente belleza natural; termas y aguas curativas de propiedades medicinales superiores a muchas de las conocidas y que se explotan en el país [...] posee uno de los cotos de ciervos más importantes del mundo que, conjuntamente con la abundancia de jabalíes, pumas y otras especies, provocan la afluencia de considerable cantidad de cazadores [...] existen lugares y parajes de interés arqueológico, paleontológico, científico, histórico, etc. Librados a un descontrolado saqueo de valiosas piezas, en su mayoría por profanos, por no existir un organismo encargado de su contralor y vigilancia...42

Desde la década del cuarenta se efectuaron diversas acciones para favorecer el arribo de excursionistas. Los primeros pasos los dio Miguel Duval, quien subrayó la necesidad de publicitar el progreso productivo y económico que el territorio había logrado. Para ello, por medio de la Comisión Oficial de Fomento, dispuso una serie de medidas como «la filmación de una película-documental, la propaganda, el fomento del turismo y la edición de folletos y obras de otra índole» que destacaran «las diversas fases de la evolución pampeana».43 Las imágenes que se mostraron en el film estaban relacionadas con el trabajo en obrajes y salinas, el desarrollo de la agricultura y la ganadería, el avance del riel y la red caminera, aspectos que sin dudas resaltaban el progreso y la grandeza de La Pampa. También existían otros intereses detrás de la filmación de este documental ya que los tres actos del filme - desierto conquistado, la tierra del caldén y la gran llanura- apuntaban a desterrar la idea de que el territorio continuaba siendo una «tierra de malones» (Etchenique y Pena 2003).

Los miembros de la Comisión intentaron fundar un imaginario, tanto a nivel nacional como territoriano, sobre lo que era La Pampa. Como plantea Paula Laguarda, ya desde fines del siglo XIX los sectores empresariales utilizaron el discurso de la modernidad para atraer inversiones y mano de obra, destinadas a sus iniciativas de colonización y producción. También recurrieron a las imágenes que documentaban los

\footnotetext{
42 Boletín Oficial de la Provincia de La Pampa, N. ${ }^{\circ}$ 261, «Decreto-Ley N. ${ }^{\circ} 2497$ del 18 de diciembre de 1959, Creando la Oficina de Turismo», Fondo de Gobierno, Archivo Histórico Provincial Profesor Fernando Aráoz. Santa Rosa-La Pampa, 1084-1805.

43 Libro de Actas de la Comisión de Propaganda y Fomento del Territorio Nacional de La Pampa, Archivo Histórico Provincial, Fondo de Gobierno (1941-1943). La filmación del documental la realizó Sucesos Argentinos y los gastos ascendieron a la suma de \$25.00o. Miguel Duval, Memoria Gráfica. Período de Gobierno 1939-1945, Santa Rosa, Gobernación de la Pampa, República Argentina, Ministerio del Interior, 1946, p. 28.
} 
avances económicos y el progreso general de la región (Laguarda 2010). Mediante el imaginario iconográfico buscaron resignificar un espacio que aún seguía asociándose con el «desierto» y la barbarie. 44

Otras gestiones que se realizaron fueron el envío de delegados pampeanos al Congreso Nacional de Turismo que se organizó en 1942 y la elaboración de un censo hotelero; 45 los integrantes de la comisión también debatieron sobre la necesidad de instalar terminales de colectivos en distintos puntos, establecer convenios para abaratar los costos de los pasajes y programaron la elaboración de una guía turística. Otros pasos importantes fueron «proyectar la reglamentación de las agencias de viaje y empresas de turismo».46

También se discutió sobre qué lugares turísticos impulsar. En el libro de actas de la comisión quedaron plasmadas las intenciones de mostrar «las bellezas naturales de la Pampa» que ofrecían a los viajeros la posibilidad de disfrutar y contemplar «las inmensas llanuras, los bosques de caldenes, las lagunas de aguas medicinales, las praderas de caza, los lugares de pesca».47 Para concretar estos objetivos había que avanzar con la reglamentación de la pesca y la caza, realizar fiestas típicas, exposiciones, concursos y programar otras iniciativas que demostraran la atracción turística de la región. ${ }^{48}$ También se promovieron las visitas a sitios históricos, al

\footnotetext{
$44 \mathrm{El}$ sentido otorgado al término desierto estuvo cargado de ambigüedad, hacia fines del siglo XIX y principios del Xx. Los territorios incorporados luego de las campañas militares se vieron revalorizados a través de su exploración y conocimiento. Eran espacios vacíos pero con tierras fértiles, como las del este pampeano o la franja andina. El término se aplicará a la «estepa patagónica y solo en el sentido de vacío de población a la zona andina». Pedro Navarro Floria, «Paisajes de un progreso incierto. La Norpatagonia en las revistas científicas argentinas (1876-1909)», en: Navarro Floria, Pedro (coord.), Paisajes del progreso. La resignificación de la Patagonia Norte, 1880-1916, Neuquén, Editorial de la Universidad Nacional del Comahue, 2007, p. 30.

45 Boletín Oficial de la Gobernación, N. ${ }^{\circ}$ 219, «Resolución No 680 del 2 de julio de 1942, Designando Delegados al Congreso de Turismo». Fondo de Gobierno, Archivo Histórico Provincial «Profesor Fernando Aráoz». Santa Rosa-La Pampa.

${ }^{46}$ Boletín Oficial de la Gobernación, «Resolución N. ${ }^{\circ} 1008$ del 22 de mayo de 1945, sobre reorganización de la Comisión Oficial de Fomento, Turismo y Deportes de La Pampa», Archivo Histórico Provincial «Profesor Fernando Aráoz», Santa Rosa-La Pampa.

47 Libro de Actas de la Comisión Oficial de Propaganda y Fomento del Territorio Nacional de La Pampa, Fondo de Gobierno, Archivo Histórico Provincial «Profesor Fernando Aráoz», Santa Rosa-La Pampa, 1942-1943, 15.

${ }^{48}$ Estas medidas si bien eran novedosas en el territorio pampeano ya habían sido expuestas en 1922 por el Touring Club Argentino, institución que propuso la creación de una «organización de fomento oficial» del turismo financiada con un impuesto a los viajeros que debería dedicarse fundamentalmente a la recopilación de la información turística y a demandar de las otras reparticiones estatales las medidas necesarias para fomentar las corrientes de viajeros, mejora de caminos, conservación de monumentos históricos, etc.» Piglia, 2008a.
} 
estudiar y proponer las mejoras necesarias para que surgiera el turismo recreativo en esos espacios. Estas medidas fueron tomadas en conjunto con la Comisión Nacional de Museos y Lugares Históricos.49 Ante las gestiones gubernamentales en 1943 obtuvieron reconocimiento como lugares históricos el paso Pacheco -río Colorado, al sur del Curacó-, Treru Lauquén -El Carancho-y Luan Lauquén -Laguna del Guanaco- .50

En consonancia con estas medidas, se trató de reorganizar el Museo Regional Pampeano, que tuvo un período de funcionamiento entre 1935 y 1937 y luego fue desmantelado. Desde la comisión se impulsó su reorganización y reanudó sus actividades en 1945 (Pera 2011). Estas acciones tenían un correlato con las premisas del gobierno nacional, al considerar que podían convertirse en atractivos turísticos los «atributos naturales, un rastro de la historia nacional, un testimonio de la modernización y la obra de gobierno» si el «Estado invertía en hoteles, caminos y propaganda (Piglia 2010).

Entre las gestiones desarrolladas también destacamos la construcción de caminos $^{51}$ y un puente en Los Tamariscos -río Colorado-, la refacción del puente de

49 Los proyectos turísticos del Estado nacional estaban en sintonía con el accionar de la Comisión Nacional de Museos y Lugares Históricos. Un claro ejemplo de ello fue la asistencia de Ricardo Levene, presidente de esa entidad, al Congreso Nacional de Turismo celebrado en 1942. Entre las propuestas de los miembros de la Comisión se destacaron: señalamiento de los lugares históricos con monolitos y letreros; acordar con la Dirección de Vialidad y el Automóvil Club Argentino la colocación de letreros indicadores de lugares históricos próximos a las carreteras; publicar guías ilustradas de los Museos Históricos para ser distribuidas gratuitamente entre el público. María S. Uribarren, A atuação da "Comisión Nacional de Museos y de Monumentos y Lugares Históricos" da Argentina entre 1938 e 1946: sua intervenção no Conjunto Jesuítico da Igreja da Companhia de Jesus e da residência dos padres na cidade de Córdoba, San Pablo, Universidade de São Paulo, 2008.

${ }^{50} \mathrm{El}$ paso Pacheco fue el lugar por donde cruzaron las tropas del General Ángel Pacheco, en 1833, en marcha hacia el sur. Treru Lauquén fue un campamento general y base de operaciones del Ejército expedicionario de Río Negro en la campaña militar realizada en 1879. Finalmente, la Laguna del Guanaco fue un sitio de paso del ejército Expedicionario al Río Negro, en la Campaña al «desierto» de

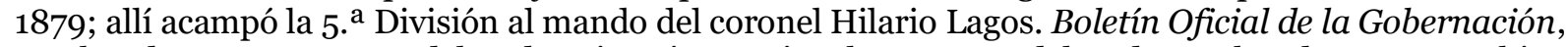
octubre de 1944, «Decreto del Poder Ejecutivo Nacional N. ${ }^{\circ}$ 11146, del 13 de octubre de 1943», Archivo Histórico Provincial «Profesor Fernando Aráoz», Santa Rosa-La Pampa.

${ }_{51}$ Durante la década del treinta las «obras camineras estuvieron a cargo de la Dirección de Puentes y Caminos la cual, con la colaboración de vecinos, de las municipalidades y comisiones de fomento, llevaba a cabo las tareas de apertura de trazas. También colaboraba con esas labores una Comisión Permanente Pro Arreglo y Conservación del Camino, designada por el Gobierno del Territorio». Javier Ayala y Santiago Gette, «Caminos y transportes». Historia de la Pampa - Sociedad, Política, Economía - Desde los poblamientos iniciales hasta la provincialización (ca. 8000 AP a 1952). Javier Ayala y Santiago Gette, «Caminos y transportes», en: Lluch, Andrea y Salomón Tarquini, Claudia (eds.), Historia de la Pampa - Sociedad, Política, Economía - Desde los poblamientos iniciales hasta la provincialización (ca. 80oo AP a 1952), Santa Rosa-La Pampa, EdUNLPam, 2014, p. 196. Con la conformación del Distrito N. ${ }^{\circ} 21$ de Vialidad Nacional, ubicado en Santa Rosa, comenzó el accionar de ese organismo en el 
Pichi Mahuida, la proyección de la ruta nacional N. ${ }^{\circ} 35$ y la edificación de algunos de sus recorridos. $\mathrm{Al}$ realizar estas obras públicas, que favorecieron un tránsito más fluido por la región, el gobierno actuaba conjuntamente con la Dirección Nacional de Vialidad. Asimismo, se montaron 33 guardaganados en el tramo comprendido entre El Carancho y La Japonesa. Estos ahorraban a los turistas las molestias de abrir y cerrar las tranqueras ubicadas en el trayecto. ${ }^{2}$ La Dirección de Parques Nacionales mostró interés en las rutas pampeanas y proyectó la construcción de dos hosterías, con comodidades para pasajeros y estaciones de servicio para automóviles. El gobernador Miguel Duval sugirió como lugares ideales para su emplazamiento «las sierras de Lihuel-Calel, sobre la ruta 152, a unos 150 kilómetros de General Acha y La Japonesa».53

La extensión de la red caminera, además de integrar el territorio y favorecer el turismo, también «ofreció a los aficionados del automovilismo deportivo nuevos escenarios y a partir de ellos comenzó a aumentar el recorrido de los grandes premios de turismo carretera».54 Este deporte era una buena excusa para la promoción de la Dirección Nacional de Vialidad, ya que demostraba el mejoramiento de los caminos. El territorio de La Pampa no permaneció ajeno a este evento deportivo. Así, el año 1942 las rutas pampeanas se convirtieron en escenario del «Gran Premio de automovilismo del sur». La segunda etapa de la carrera comenzó en la ciudad de General Pico y pasó por los pueblos pampeanos de Metileo, Monte Nievas, Eduardo Castex, Santa Rosa, Ataliva Rosa, General Acha, Gamay, Unanue, Epu-pel, Perú, La Cotita, Hucal, Abramo, Bernasconi, Villa Alba, Anzoátegui, Puente Río Colorado y continuó por varios lugares de Río Negro. Los medios de comunicación, nacionales y locales, replicaban los

Territorio pampeano. Fue recién a partir de la segunda mitad de la década del cuarenta que se realizaron obras de envergadura en La Pampa.

$5^{2}$ Duval, 1946.

53 Ídem.

54 Véase Pastoriza y Torre, 2002. A partir de 1937, el recorrido del turismo carretera fue de 6894 Km., en un trayecto que cruzó el litoral, prosiguió por las provincias del norte, para arribar, luego de pasar por la precordillera-Bahía Blanca-a La Plata. En 1940, el número de kilómetros recorridos aumentó a 9500, el recorrido comenzó en Buenos Aires, llegando hasta Lima para emprender el camino de regreso a Buenos Aires. Sobre el desarrollo del automovilismo en Argentina véase Eduardo Archetti, El potrero, la pista y el ring. Las patrias del deporte argentino, Buenos Aires: Fondo de Cultura Económica, 2001. Sobre turismo carretera durante la década del treinta examínense los aportes de Ballent, 2008. Piglia, Melina, «Viaje deportivo, nación y territorio. El Automóvil Club Argentino y los orígenes del Turismo Carretera. Argentina, 1924-1938», Nuevo Mundo Mundos Nuevos, [en línea], 2008c, pp. 1-15. 
recorridos, describían los paisajes y de esa forma promocionaban diversos espacios turísticos.

Durante la gestión de Juan L. Paez, 55 continuaron los esfuerzos para culminar la ruta entre Catriló y La Japonesa, trayecto que conducía a los lagos del sur, y se proyectaron otros itinerarios. Para el año 1950 los tramos de ruta pavimentada eran exiguos, ascendían a $74 \mathrm{~km}$. Las rutas nacionales N..$^{\circ} 5$ - paralela al ramal Once-Toayy la N. ${ }^{\circ} 35$ estaban entoscadas y en proceso de colocación de la carpeta asfáltica. La última de las arterias, que provenía del norte argentino y llegaba hasta General Acha, empalmaba allí con la ruta nacional N. ${ }^{0} 152$ que conducía a El Carancho donde desviaba hacia Los Tamariscos y La Japonesa. Esta obra vial, según las autoridades estatales, generó un «vigoroso impulso a la economía regional y nacional» ya que el puente sobre el río Colorado entroncaba la ruta $\mathrm{N} .^{\circ} 152$ con «las carreteras rionegrinas que llevan directamente a los Lagos del Sud, atravesando el territorio de Neuquén».56 Las autoridades resaltaban así la importancia de esa red caminera que conducía a los parques Nahuel Huapi, Lanín, Copahue, Pino Hachado, San Martín de los Andes, San Carlos de Bariloche, entre otros destinos. Además, ensamblaba esos puntos con Capital Federal, el litoral y el centro de la República al empalmar con las rutas N. ${ }^{\circ} 5$ y N. ${ }^{\circ} 35$.

En el año 1953 un representante de la Provincia asistió a la reunión de Coordinación Nacional e Interprovincial del Turismo, celebrada en la ciudad de Santiago del Estero; 57 también se aprobó la Ley N. ${ }^{\circ} 50$ sobre caza y protección de la fauna silvestre, $5^{8}$ además de realizar licitaciones para la construcción de trayectos viales. A inicios de 1960 se impulsó un plan de obras públicas, que contemplaba al sector turismo. Preveía la culminación de edificaciones en curso, como la estación terminal de la ciudad de Santa Rosa, e iniciar otros trabajos en conjunto con la

\footnotetext{
55 Gobernó el Territorio Nacional de La Pampa entre noviembre de 1946 y septiembre de 1948.

${ }_{5}^{6}$ Boletín Oficial de la Gobernación, «Desarrollo del Plan Quinquenal en La Pampa», Fondo de Gobierno, Archivo Histórico Provincial «Profesor Fernando Aráoz». Santa Rosa-La Pampa, 1947, pp. 24-25.

57 Boletín Oficial de la Provincia Eva Perón, N. ${ }^{\circ}$ 5, «Decreto N. ${ }^{\circ}$ 478, «Aprobando la actuación del representante del Gobierno de la Provincia en la reunión de Coordinación Nacional Interprovincial del Turismo», Fondo de Gobierno, Archivo Histórico Provincial «Profesor Fernando Aráoz». Santa RosaLa Pampa, 1953, p. 27.

${ }^{8}$ La Dirección General de Asuntos Agrarios, por intermedio de la Dirección de Defensa de la Producción Agropecuaria, era la repartición encargada de aplicar esa legislación. Boletín Oficial de la Provincia Eva Perón, N. ${ }^{\circ}$ 9, Fondo de Gobierno, Archivo Histórico Provincial «Profesor Fernando Aráoz». Santa RosaLa Pampa, enero de 1954: 14. Esta ley se reglamentó mediante el decreto 888/54. Consultar el Boletín Oficial de la Provincia Eva Perón, Boletín oficial N. ${ }^{\circ}$ 14-30 de junio de 1954, pp. 11-15.
} 
Dirección Nacional de Turismo. También en el presupuesto se destinaron partidas importantes para infraestructura en caminos.59 Otras diligencias efectuadas desde la Oficina de Turismo fueron la obtención de 4150 plazas de turismo social en Chapadmalal y Embalse Río III que se distribuyeron entre empleados, docentes, jubilados y trabajadores independientes», la confección de «fichas de ciudades, pueblos, lugares y parajes de La Pampa para [su] [...] catastro de los mismos», la elaboración de una «guía de transportes», un registro de «hoteles y afines con sus respectivas tarifas». Además, conjuntamente con las autoridades del ACA acordaron la construcción y explotación de estaciones de servicio en Lihuel Calel y La Japonesa y se firmó un convenio para confeccionar e imprimir un «folleto desplegable de interés turístico, con un gran mapa de la provincia».60 Asimismo, la oficina proyectó la publicación de 4000 ejemplares de una Guía de La Pampa. Además, entregó material informativo al ACA sobre lugares para la caza deportiva con la intención de difundir ese deporte que, desde el discurso oficial, podría constituirse para la provincia en «una insospechada fuente turística».61

Como ya anticipamos, en el marco de las políticas desarrollistas, el turismo según el gobernador Ismael Amit se convertiría en una importante fuente de divisas para el país y estimularía la economía regional, para ello era necesaria «la promoción de la hotelería y la utilización óptima del paisaje patagónico».62 En ese sentido, se aprobó la Ley N. ${ }^{\circ} 274$ que favoreció la construcción de hoteles. «Con sus beneficios pudieron realizarse o ampliarse dos grandes hoteles en Santa Rosa, y los de General Pico, Macachín y Realicó».63 Estas acciones se enmarcaron en la política del Estado nacional, que durante el gobierno de Onganía buscó consolidar «una infraestructura altamente compleja de la que el país carecía: hoteles de cinco estrellas, aeropuertos internacionales, óptimos servicios de transporte»; ello se concretó con «la sanción de

\footnotetext{
59 Boletín Oficial de la Provincia de La Pampa, N. ${ }^{\circ}$ 271, «Decreto-Ley N. ${ }^{\circ} 271$ del 9 de febrero de 1960, Aprobando un Plan de Obras Públicas», Fondo de Gobierno, Archivo Histórico Provincial «Profesor Fernando Aráoz», Santa Rosa-La Pampa, 1960, p. 150-156.

6o Reseña de la obra ejecutada por el Gobierno Provincial desde mayo de 1958 a 1960, Buenos Aires, Cooperativa Poligráfica Editora Mariano Moreno, 1961, p. 48.

${ }^{61}$ Reseña de la obra ejecutada por..., p. 113. La Capital, Santa Rosa-La Pampa, 23 de septiembre de 1964.

${ }^{62}$ La Capital [Santa Rosa-La Pampa], 8 de septiembre de 1965, 4.

${ }_{63}$ Helvio Gouzden, Cuatro años de gobierno en La Pampa, 1966 -3o de junio- 1970. Santa Rosa-La Pampa: Imprenta Oficial, Consejo Provincial de Difusión, 1970, p. 53.
} 
un decreto por el que se otorgaron amplias facilidades para la edificación de hoteles de primera calidad, inexistentes en la Argentina (Pastoriza 2008 13)».

A mediados de los años sesenta, desde el Departamento de Turismo, se iniciaron las gestiones para la adquisición de más de ocho mil hectáreas y el castillo de la estancia San Huberto. Ese predio, que comenzó a denominarse Parque Luro, 64 fue reservado como lugar de recreo y para la práctica de la caza.65 Se ambientó con algunos hospedajes y un sector para camping con agua, baños y fogones. Finalmente, y en el marco de una concepción integral del Parque Luro como sitio destinado al turismo, el gobierno proyectó «la construcción de cocheras, canchas de tenis, bochas, golf, pelota a paleta y polo» y completarían el equipamiento «una pileta de natación».66 En la misma época el Estado provincial expropió una superficie de 10.500 hectáreas, en conjunto con la Dirección General de Parque Nacionales, para crear el Parque Nacional de Lihuel Calel. ${ }^{67}$

En octubre del año 1969, La Pampa participó de la II Reunión de la Junta de Gobernadores de la Región de desarrollo Comahue. Allí se firmó un acta final que contempló distintos objetivos en materia de políticas turísticas y las estrategias a implementar para su cumplimiento.68 Los representantes de la provincia desempeñaron en esa época la «presidencia del Comahue turístico, organismo que

\footnotetext{
64 Está ubicado en el departamento Toay a $35 \mathrm{~km}$ de la ciudad de Santa Rosa. Las tierras que forman el Parque Luro pertenecieron a Ataliva Roca, que luego las legó a su hija Arminda. El esposo de esta, Pedro Olegario Luro, instaló allí el primer coto de caza privado. Importó especies animales como el Cervus elaphus, jabalíes y faisanes. En el año 1939 Antonio Maura y Gamazo compró esas propiedades. Luego de su fallecimiento, su hija Inés Maura de Roviralta, vendió parte de las tierras al Gobierno de la provincia. Evar Orlando Amieva, El Parque Luro, (Santa Rosa-La Pampa, Fondo Editorial Pampeano, 1993.

65 Parque Luro, Biblioteca Pampeana, Serie Folletos N. ${ }^{0}$ 16, La Pampa, Consejo Provincial de Difusión del Gobierno de La Pampa, 1972.

66 Parque Luro..., pp. 8-10. Muchas de estas obras pudieron concretarse por un aporte de 100 millones de pesos nacional, otorgados por la Dirección Nacional de Turismo, al que se sumó el apoyo del Destacamento de Exploración de Caballería Blindada 101. Gouzden, Cuatro años..., pp. 49-50.

${ }^{67}$ Boletín Oficial de la Provincia de La Pampa, N. ${ }^{\circ}$ 504, «Ley N. ${ }^{\circ} 307$ del 14 de agosto de 1964, Declárase de utilidad pública y sujeto a expropiación un inmueble», Fondo de Gobierno, Archivo Histórico Provincial Profesor Fernando Aráoz. Santa Rosa-La Pampa, 561. La Capital, Santa Rosa-La Pampa, 23 de septiembre de 1964. El aporte de un total de cien millones de pesos nacional, otorgados por la Dirección Nacional de Turismo, más el apoyo eficaz del Destacamento de Exploración de Caballería Blindada 101, permitieron el desarrollo de ese ambicioso proyecto sin mayor incidencia sobre el presupuesto provincial.

68 II Reunión de la Junta de Gobernadores de la Región de desarrollo Comahue. Acta final, 23 y 24 de octubre de 1969.
} 
nucleaba a las direcciones de turismo de las jurisdicciones de La Pampa, Río Negro, Neuquén, Chubut y partidos del sur de Buenos Aires» (Trapaglia 1973).

Durante la década siguiente continuó la participación en el Comahue Turístico; ${ }^{69}$ el diseño de políticas sobre la temática llevó a los gobernantes a poner especial cuidado en la selección del personal que las gestionara. Se publicaron diversas guías como las de «25 de Mayo, Santa Rosa, General Pico, General Acha, Victorica e Intendente Alvear, y Guía Hotelera de La Pampa» (Trapaglia 83). En estos años destacamos la preparación de documentación y un proyecto básico para la Dirección de Turismo, la apertura de un registro de campos para caza mayor y menor, el relevamiento hotelero provincial, la realización en Santa Rosa de la VII Reunión Nacional de Turismo, el relevamiento de las necesidades de los clubes de caza deportiva y la apertura del registro de guías de caza. ${ }^{70}$

\section{Comentarios finales}

La implementación de políticas públicas sobre turismo por parte del Estado nacional encontró respuestas al interior del país. En el caso de La Pampa, desde fines de la década del treinta se fue posicionando en la agenda pública la cuestión del turismo. Los mandatarios de turno pusieron en práctica diversas acciones al respecto y de ese modo se aprobaron normativas y crearon organismos que tenían como propósito fomentar el territorio, publicitar su «progreso» y estimular las prácticas turísticas. Para atraer a los excursionistas había que realizar campañas que promocionaran el aprovechamiento y desarrollo de las lagunas de aguas medicinales, las excelentes condiciones de los bosques de caldenes para el camping, ejecutar obras de interés turístico, impulsar visitas a los lugares históricos, promover y regular la pesca y la caza, entre muchas otras gestiones.

Las sucesivas autoridades gubernamentales resaltaron la posición estratégica del territorio pampeano ubicado en el centro del país, y por ello lugar de paso obligado, tanto de las corrientes turísticas que se dirigían al norte como al sur. Con el objeto de atraer esos flujos, entre los años cuarenta y sesenta, concretaron obras viales y

\footnotetext{
69 Mensaje del gobernador Aquiles José Regazzoli ante la Legislatura Provincial, 9 de abril de 1974.

70 Memoria del Gobierno de La Pampa, 29/3/1976 al 15/2/1977, Santa Rosa, Secretaría de Difusión y Turismo, Talleres de la Dirección de Prensa-Provincia de La Pampa, 1977.
} 
mantuvieron los caminos existentes, construyeron infraestructura hotelera y reglamentaron la caza y la pesca.

Advertimos que una de las mayores dificultades para poner en marcha estas políticas fue la escasez de recursos financieros. Muchas de las agencias creadas vieron limitado su accionar por esta problemática y la ejecución de políticas fue, en algunas oportunidades, más una expresión de deseos que la culminación de acciones concretas. Consideramos que esta situación se revierte modestamente a principios de los años sesenta, ya que en presupuesto provincial se asignaron partidas específicas para la puesta en marcha de esas políticas.

En esta aproximación al estudio del desarrollo turístico en el territorio de La Pampa, nos concentramos en mayor medida en las gestiones de uno de los sectores involucrados, el Estado. También fueron interpelados otros actores de la sociedad civil que se convirtieron en interlocutores del proceso de gestación y aplicación de las políticas. En este sentido, nos quedan varios interrogantes por responder y aspectos para ahondar, como los vínculos que el Estado entabló con los propietarios hoteleros o de las empresas de transporte y las respuestas de otros actores de la sociedad civil. Asimismo, sería interesante profundizar en el perfil de los funcionarios y encargados de implementar esas políticas para conocer cuáles eran los saberes expertos que poseían.

Al llegar a los años ochenta en una publicación oficial se expuso: «no hace mucho tiempo los pampeanos hemos descubierto que la palabra turismo tiene su aplicación práctica dentro de nuestra provincia». Sus páginas destacaron la importancia de la infraestructura vial, que permitía a los viajeros desplazarse en forma rápida por el centro del país; también mencionaron como lugares turísticos el Parque Luro, las termas de Bernardo Larroudé, la laguna de Guatraché y las sierras de Lihue Calel. Asimismo, aludieron a la importancia de la caza mayor y la atracción de aquellos que practicaban ese deporte. Finalmente, el escrito dejó al descubierto una de las mayores dificultades a la hora de captar a los viajeros ya que, «para la mayoría de los turistas argentinos», La Pampa era solamente un lugar de «paso».71

\section{Fuentes y obras citadas}

${ }^{71}$ La Pampa, c. 1980, p. 9. 


\section{Fuentes}

Boletines Oficiales de la Gobernación de La Pampa. Fondo de Gobierno, Archivo Histórico Provincial Profesor Fernando Aráoz. Santa Rosa-La Pampa, 19401951.

Boletines Oficiales de la Provincia Eva Perón. Fondo de Gobierno, Archivo Histórico Provincial Profesor Fernando Aráoz. Santa Rosa-La Pampa, 1951-1955.

Boletines Oficiales de la Provincia de La Pampa. Fondo de Gobierno, Archivo Histórico Provincial Profesor Fernando Aráoz. Santa Rosa-La Pampa, 1955-1960.

COMISIÓN ECONÓMICA PARA AMÉRICA LATINA-CONSEJO ECONÓMICO Y SOCIAL, «Resolución N. ${ }^{\circ} 56$ del 25 de abril de 1953". Suplemento N. ${ }^{\circ} 3$, Disponible en: http://repositorio.cepal.org/bitstream/handle/11362/15630/RES-056-S$\underline{\mathrm{V} \text { es.pdf }}$

Duval, Miguel, Memoria presentada al Superior Gobierno de la Nación, Período: 1940-1941, Santa Rosa: Talleres Gráficos de la Gobernación de la Pampa, 1941.

-_-_- Memoria Gráfica. Período de Gobierno 1939-1945, Santa Rosa, Gobernación de la Pampa, República Argentina, Ministerio del Interior, 1946.

Gouzden, Helvio, Cuatro años de gobierno en La Pampa, 1966 -3o de junio- 1970. Santa Rosa-La Pampa: Imprenta Oficial, Consejo Provincial de Difusión, 1970.

La Capital, Santa Rosa-La Pampa, 1963-1966.

La Pampa Hoy. Biblioteca Pampeana. Serie Folletos. Santa Rosa, Talleres Gráficos de La Pampa, 1969.

La Pampa. Su realidad en: cifras demostrativas e información general, Santa RosaLa Pampa, Secretaría de Difusión y Turismo Dirección de Prensa, c.a.1980.

Libro de Actas de la Comisión Oficial de Propaganda y Fomento del Territorio Nacional de La Pampa, Fondo de Gobierno, Archivo Histórico Provincial «Profesor Fernando Aráoz», Santa Rosa-La Pampa, 1942-1943.

Libro de Actas de la Comisión de Fomento, Turismo y Deporte, Fondo de Gobierno, Archivo Histórico Provincial «Profesor Fernando Aráoz», Santa Rosa-La Pampa, 1943-1947.

Mensaje del Gobernador Aquiles José Regazzoli ante la Legislatura Provincial, 9 de abril de 1974 .

Memoria del Gobierno de La Pampa, 29/3/1976 al 15/2/1977, Santa Rosa, Secretaría de Difusión y Turismo, Talleres de la Dirección de Prensa-Provincia de La Pampa, 1977.

Parque Luro, Biblioteca Pampeana, Serie Folletos N. ${ }^{\circ}$ 16, La Pampa: Consejo Provincial de Difusión del Gobierno de La Pampa, 1972.

República Argentina, Presidencia de la Nación, Subsecretaría de Informaciones, Segundo Plan Quinquenal (1952-1957), Buenos Aires, 1953.

República Argentina, "Decreto Nacional N. 9468 del 19 de octubre de 1961, Reglamentario de la Ley N. ${ }^{\circ}$ 14574". Disponible en: http://www.saij.gob.ar/9468-nacional-decreto-reglamentario-ley-14574sobre-direccion-nacional-turismo-dn19610009468-1961-10-19/123456789oabc-864-9000-1691soterced 
-_-—— «Ley N. ${ }^{\circ}$ 17752, del 27 de mayo de 1968, Promoción de la construcción de hoteles de turismo internacional.» Disponible en: http://servicios.infoleg.gob.ar/infolegInternet/anexos/230000234999/232558/norma.htm

- - - - «Decreto N. ${ }^{\circ}$ 3091, del 3 de junio de 1968, reglamentario de la Ley N. ${ }^{0} 17752$ sobre Promoción de la construcción de hoteles de turismo internacional». Disponible en: http://www.saij.gob.ar/3091-nacional-decreto-nacional-ley17752-sobre-promocion-construccion-hoteles-turismo-internacionaldn19680003091-1968-06-03/123456789-0abc-190-3000-8691soterced

- - - - «Ley N. ${ }^{\circ} 18828$ del 6 de noviembre de 1970, sobre Reglamentación Hotelera». Disponible en: http://servicios.infoleg.gob.ar/infolegInternet/anexos/23000o234999/231822/norma.htm

- - - - «Ley N. ${ }^{\circ} 18829$ del 6 de noviembre de 1970, sobre Reglamentación de los agentes de viaje». Disponible en: http://servicios.infoleg.gob.ar/infolegInternet/anexos/2500029999/27128/norma.htm

-_--— «Ley N. ${ }^{0}$ 19644, del 16 de mayo de 1972, Apruébanse los Estatutos de la Organización Mundial del Turismo». Disponible en: http://servicios.infoleg.gob.ar/infolegInternet/anexos/215000219999/217313/norma.htm

- - - - «Ley N. ${ }^{\circ} 21056$ del 17 de septiembre de 1975, sobre Medidas promocionales sobre turismo en Transportes de media y larga distancia». Disponible en: https://leyesargentinas.com/norma/233112/ley-21056-turismo-transportesde-media-y-larga-distancia-medidas-promocionales\#texto-original

Reseña de la obra ejecutada por el Gobierno Provincial desde mayo de 1958 a 196o, Buenos Aires, Cooperativa Poligráfica Editora Mariano Moreno, 1961.

II Reunión de la Junta de Gobernadores de la Región de desarrollo Comahue, Acta final 23 y 24 de octubre de 1969.

Trapaglia, Ángel Benjamín Santos, 2 años de gobierno en La Pampa. 1971 -mayo1973. Santa Rosa-La Pampa: Talleres Gráficos de la División Imprenta, Consejo Provincial de Difusión, 1973.

\section{Bibliografía}

Almirón, Analía; Bertoncello, Rodolfo; Kuper, Diego y Ramírez, Lucas, «El turismo como impulsor del desarrollo en Argentina. Una revisión de los estudios sobre la temática», Aportes y transferencias, Año 12, Vol. 1, 2008, pp. 56-86. Disponible en: http://nulan.mdp.edu.ar/363/.

Alonso, Fabio, «Transformaciones políticas en La Pampa ¿hacia un estado peronista?», 4. ${ }^{a s}$ Jornadas de Historia de La Patagonia, 2010.

Amieva, Evar Orlando El Parque Luro. Santa Rosa-La Pampa: Fondo Editorial Pampeano, 1993.

Archetti, Eduardo, El potrero, la pista y el ring. Las patrias del deporte argentino. Buenos Aires: Fondo de Cultura Económica, 2001.

Ayala, Javier y Gette, Santiago, «Caminos y transportes», en: Lluch, Andrea y Salomón Tarquini, Claudia (eds.), Historia de la Pampa - Sociedad, Política, Economía - 
Desde los poblamientos iniciales hasta la provincialización (ca. 8000 AP a 1952), Santa Rosa-La Pampa, EdUNLPam, 2014, pp. 191-200.

Ballent, Anahí, «Kilómetro cero: la construcción del universo simbólico del camino en la Argentina de los años treinta», Boletín del Instituto de Historia Argentina Americana Dr. Emilio Ravignani, N. ${ }^{\circ}$ 27, 2005, pp. 107-136. Disponible en: https://www.redalyc.org/pdf/3794/379444921004.pdf.

- - - - «Ingeniería y Estado: la red de caminos y las obras públicas en Argentina, 1930-1943», Historia, Ciencia e Saude-Manguinhos, Vol. 15, N. ${ }^{3}$, 2008, pp. 827-847. Disponible en: https://www.scielo.br/scielo.php?pid=So10459702008000300013\&script=sci_arttext.

Ballent, Anahí y Gorelik, Adrián, «País urbano o país rural: la modernización territorial y su crisis», en: CATTARUZZA, AlEJANDRO (dir.), Crisis económica, avance del Estado e incertidumbre política (1930-1943), Buenos Aires, Sudamericana, 2001.

Berrotarán, Patricia, «Guiso de liebre sin liebre: Estado, burocracias y peronismo», en: Plotkin, Mariano y Zimmermann, Eduardo (comps.), Las prácticas del Estado. Política, sociedad y elites estatales en la Argentina del siglo XX, Buenos Aires: Edhasa, 2012, pp. 131-155.

Capanegra, Alejandro, «El desarrollo turístico como estrategia política del estado: de la política en turismo a la política turística. Argentina 1900-1975», Aportes y Transferencias, Vol. 14, N. ${ }^{\circ}$ 1, 2010, pp. 23-42. Disponible en: http://nulan.mdp.edu.ar/1485/.

- - - - «Política turística Argentina 1956-1976. De la agenda social a la agenda económica», ponencia presentada en el VI Congreso Latinoamericano de Investigación Turística, Neuquén, 2014.

Etchenique, Jorge y Pena, Cristian, Apuntes para una historia del cine en el Territorio Nacional de La Pampa, La Pampa, Ministerio de Cultura y Educación, 2003.

Jáuregui, Aníbal, «La planificación en Argentina: el Conade y el PND (1960-1966)», Anuario del Centro de Estudios Históricos «Prof. Carlos S. A. Segreti», Año 13, N. $13, \quad 2013$, pp. 265-266. Disponible en: https://revistas.psi.unc.edu.ar/index.php/anuarioceh/article/view/22171.

Khatchikian, Miguel y Murray, María Cristina, «Turismo social: el paraíso perdido», Nexos, Vol. 6, N. ${ }^{\circ}$ 11, 1999, pp. 12-17. Disponible en: http://nulan.mdp.edu.ar/417/1/o0483.pdf

Laguarda, Paula, «Vender las pampas: El imaginario de la modernización y la fotografía propagandística en el Territorio Nacional de La Pampa», Quinto Sol, N. ${ }^{\circ}$ 14, 2010, pp. 49-74.

Méndez, Laura, Estado, frontera y turismo. Historia de San Carlos de Bariloche, Buenos Aires, Prometeo, 2010.

- « «urismo de elite y turismo social en el «Edén de América». El parque Nacional Nahuel Huapi entre 1934 y 1955», Textos y contextos desde el sur, Vol. II, N. ${ }^{\circ}$ 4, 2016, pp. 13-30. Disponible en: http://www.revistas.unp.edu.ar/index.php/textosycontextos/article/view/35.

Navarro Floria, Pedro, «Paisajes de un progreso incierto. La Norpatagonia en las revistas científicas argentinas (1876-1909)», en: NAVARRO FLORIA, PEDRO 
(coord.), Paisajes del progreso. La resignificación de la Patagonia Norte, 18801916, Neuquén, Editorial de la Universidad Nacional del Comahue, 2007.

- «La "Suiza argentina", de utopía agraria a postal turística: la resignificación de un espacio entre los siglos XIX y XX», $3{ }^{a s}$ Jornadas de Historia de la Patagonia, 2008, pp. 1-23.

- - - - - y Vejsberg, Laila, «El proyecto turístico barilochense antes de Bustillo. Entre la prehistoria del Parque Nacional Nahuel Huapi y el desarrollo local», Estudios $y$ perspectivas en turismo, Vol. 18 , N. ${ }^{\circ} 4$, 2009, pp. 414-433. Disponible en: https://www.redalyc.org/pdf/1807/180714241004.pdf.

Núñez, Paula y Vejsbjerg, Laila, «El turismo, entre la actividad económica y el derecho social. El Parque Nacional Nahuel Huapi, Argentina, 1934-1955», Estudios y Perspectivas en Turismo, Vol. 19, N. ${ }^{\circ}$ 6, 2010, pp. 930-945. Disponible en: https://www.redalyc.org/pdf/1807/180717577004.pdf

Ospital, María Silvia, «Turismo y territorio nacional en Argentina. Actores sociales y políticas públicas, 1920-1940», EIAL, Vol. 16, N. ${ }^{\circ}$ 2, 2005, pp. 63-84. Disponible en:

https://scholar.google.com/scholar_url?url=http://eial.tau.ac.il/index.php/ei al/article/download/346/315\&hl=en\&sa=T\&oi=gsb-

ggp\&ct $=$ res\&cd $=0 \& d=14798072737143359314 \&$ ei $=$ eVfUXqOjEPiLy9YPheOtk AQ\&scisig=AAGBfm1tJtGTPERslVoVmmmRR4VDXZ1yfA.

Oszlak, Oscar y O’Donnell, Guillermo, «Estado y políticas estatales en América Latina: hacia una estrategia de investigación», Doc. CEDES/G.E, Clacso/ N. ${ }^{\circ} 4$, Buenos Aires, Clacso, 1976.

Pastoriza, Elisa, «El turismo social en la Argentina durante el primer Peronismo. Mar del Plata, la conquista de las vacaciones y los nuevos rituales obreros, 19431955», Nuevo Mundo Mundos Nuevos [en línea], puesto en línea el 16/6/2008, pp. 1-14. doi: 10.4000/nuevomundo.36472

- - - - «Estado, gremios y hoteles. Mar del Plata y el peronismo», Revista Estudios Sociales, N. ${ }^{\circ} 34,2008$, pp. 121-147.

--_-_ La conquista de las vacaciones. Breve Historia del turismo en Argentina, Buenos Aires, Edhasa, 2011.

- - - - - y Pedetta, Marcelo, «Lo que el pueblo necesita. Turismo social y Peronismo. Argentina, 1945-1955», Études Caribéennes, Vol. 13-14, 2009, pp. 1-20. Disponible en: https://journals.openedition.org/etudescaribeennes/3767.

Pastoriza, Elisa y Piglia, Melina, «Asociaciones civiles, empresas y Estado en los orígenes del turismo argentino», Anuario IEHS, Vol. 27, 2012, pp. 393-415. Disponible en: http://anuarioiehs.unicen.edu.ar/Files/2012/Dossier\%20pastoriza/Asociacio nes\%20civiles.pdf.

Pastoriza, Elisa y Torre, Juan Carlos, «Mar del Plata, un sueño de los argentinos», en: DEVOTO, FERNANDO y MADERO, MARTA (eds.), Historia de la vida privada en la Argentina, Buenos Aires, Taurus, 1999, pp. 49-77.

-_-_- «La democratización del bienestar», en: Torre, Juan Carlos (ed.), Los años peronistas (1943-1955), Buenos Aires, Sudamericana, 2002, pp. 257-313. 
Pera, Lía M., «La formación museográfica de las colecciones arqueológicas. El caso del Museo Provincial de Historia Natural de La Pampa», en: Actas de las IV Jornadas de Historia Social de la Patagonia, Santa Rosa-La Pampa, Universidad Nacional de La Pampa, 2011.

Piantoni, Giulietta; BARrios García, Gonzalo y Pierucci, LilianA, "Las bellezas panorámicas argentinas: una revisión histórica de las políticas públicas y el desarrollo del turismo en el Parque Nacional Nahuel Huapi durante el peronismo (1943-1955)», Pasado Abierto, N. ${ }^{0}$ 9, 2019, pp. 236-255. Disponible en: https://rid.unrn.edu.ar/jspui/handle/20.500.12049/3873

Piglia, Melina, «La incidencia del Touring Club Argentino y del Automóvil Club Argentino en la construcción del turismo como cuestión pública: 1918-1929», Estudios, Perspectivas, Turismo, Vol. 17, N. ${ }^{0}$ 1, 2008a, pp. 51-70. Disponible en: https://www.redalyc.org/pdf/1807/180713894003.pdf.

- - - - «Asociaciones civiles y estado en los años veinte: intervenciones del Automóvil Club Argentino y del Touring Club Argentino en vialidad y turismo», EIAL, Vol. 19, N. ${ }^{\circ}$ 2, 2008b, pp. 119-140. Disponible en: https://scholar.google.com/scholar_url?url=http://www3.tau.ac.il/ojs/index. $\mathrm{php} /$ eial/article/view/570\&hl=en\&sa $=\mathrm{T} \& 0 \mathrm{i}=\mathrm{gsb} \& \mathrm{ct}=\mathrm{res} \& \mathrm{~cd}=\mathrm{o} \& \mathrm{~d}=125369957$ 24080164270\&ei=kljUXvYwgq2ZAY3gk8AK\&scisig=AAGBfm26qsvRQvK1Lin X8JCMMb5HDNhlQw.

- - - « «iaje deportivo, nación y territorio. El Automóvil Club Argentino y los orígenes del Turismo Carretera. Argentina, 1924-1938», Nuevo Mundo Mundos Nuevos, [en línea], 2008c, pp. 1-15.

- - - « «De la Dirección de Parques Nacionales, a la Administración General de Parques Nacionales y Turismo: primeras experiencias de una política turística nacional centralizada (1934-1950)», V Jornadas de Historia Política «Las provincias en perspectiva comparada», 2010.

- - - - «El despertar del turismo: primeros ensayos de una política turística en la Argentina (1930-1943)», Journal of Tourism History, Vol. 13, 2011, pp. 57-74. Disponible en: https://repotur.yvera.tur.ar/bitstream/handle/123456789/135/piglia2.pdf?se quence $=1$ \&isAllowed $=\mathrm{y}$.

- - - - «En torno a los Parques Nacionales: primeras experiencias de una política turística nacional centralizada en la Argentina (1943-1950)», Pasos. Revista de Turismo y Patrimonio Cultural, Vol. 10, N. ${ }^{0}$ 1, 2012, pp. 61-73. Disponible en: https://www.redalyc.org/pdf/881/88123053006.pdf

---_-Autos, rutas y turismo: El Automóvil Club Argentino y el Estado. Buenos Aires: Siglo Veintiuno Editores, 2014.

«Turismo en automóvil en Argentina (1920-1950)», Tiempo Social, Revista de Sociología da UPS, Vol. 30, N. ${ }^{0}$ 2, 2018, pp. 87-111. Disponible en: https://www.scielo.br/scielo.php?pid=So103-

20702018000200087\&script=sci_arttext.

Salerno, Elena, «Los inicios del turismo y los ferrocarriles del Estado en Argentina en las primeras décadas del siglo XX», VI Congreso de Historia Ferroviaria, 2012, pp. 1-18. 
Scarzanella, Eugenia, «El ocio peronista: vacaciones y «turismo popular» en Argentina (1943-1955)», Entrepasados, N. ${ }^{0}$ 14, 1998, pp. 65-84.

- - - - «Las bellezas naturales y la nación: los parques nacionales en Argentina en la primera mitad del siglo XX», Revista Europea de Estudios Latinoamericanos $y$ del Caribe, N. ${ }^{\circ}$ 73, 2002, pp. 5-21. Disponible en: https://www.jstor.org/stable/25675985

Schenkel, Erica, «La política turística como alternativa económica en la Argentina», Pasos. Revista de Turismo y Patrimonio Cultural, Vol. 13, N. ${ }^{\circ}$ 3, 2015, pp. 619628.

Disponible http://www.pasosonline.org/Publicados/13315/PSo315_12.pdf.

en:

- - - - y AlmEIDA, FERNANDO, «La política turística y la intervención del Estado. El caso de Argentina», Perfiles Latinoamericanos, Vol. 46, N. ${ }^{\circ}$ 23, 2015, pp. 197221. Disponible en: http://www.scielo.org.mx/scielo.php?pid=So188$76532015000200008 \&$ script $=$ sci_arttext\&tlng=en.

Troncoso, Claudia y Lois, Carla, «Políticas turísticas y peronismo. Los atractivos turísticos promocionados en Visión de Argentina (1950)», Pasos. Revista de turismo y Patrimonio Cultural, Vol. 2, N.o 2, 2004, pp. 281-294. Disponible en: http://www.pasosonline.org/Publicados/2204/PASOSo4.pdf\#page=137.

Uribarren, María S., A atuação da "Comisión Nacional de Museos y de Monumentos y Lugares Históricos" da Argentina entre 1938 e 1946: sua intervenção no Conjunto Jesuítico da Igreja da Companhia de Jesus e da residência dos padres na cidade de Córdoba, San Pablo, Universidade de São Paulo, 2008.

Zink, Mirta; Moroni, Marisa; Asquini, Norberto y Folco, María Esther, «Historia política, orden institucional y construcción de ciudadanía en La Pampa», en: Lluch, Andrea y Di Liscia, María Silvia (eds.), Historia de La Pampa II. Sociedad, política y economía de la crisis del treinta a inicios del nuevo siglo, Santa Rosa, EdUNLPam, 2011, pp. 85-129. 